\title{
Glucose Control: non-insulin therapies*
}

The Society for Endocrinology, Metabolism and Diabetes of South Africa Type 2 Diabetes Guidelines Expert Committee. *Chapter 9. Glucose Control: non-insulin therapies in 2017 SEMDSA Guideline for the Management of Type 2 Diabetes Guideline Committee. JEMDSA 2017; 21(1)(Supplement 1): S39-48.

\begin{abstract}
About
DPP-4: dipeptidyl peptidase-4

GLP-1: glucagon-like peptide-1

SGLT2- sodium-glucose linked transporter-2
\end{abstract}

This chapter summarises information for each of the non-insulin drug classes that are used for blood glucose control. Each summary is accompanied by a table of recommendations to guide the clinical use of these medications. For the sake of completeness, and for those that are interested, we have included a more detailed review of each drug as an appendix to each summary. These can be found in the Appendix section of the guidelines. The treatment recommendations for each drug have been incorporated into the treatment algorithm in Chapter 11. The following abbreviations are used in this chapter:

\section{1: Drug Summary - Metformin}

SEMDSA Type 2 Diabetes Guideline Expert Committee

\section{(Refer to appendix 9.1 for full text and references)}

\begin{tabular}{ll}
\hline Mechanism of Action & $\begin{array}{l}\text { Metformin targets the liver, skeletal muscle and the gut to reduce hepatic glucose output, increase skeletal muscle } \\
\text { glucose uptake, increase GLP-1 levels and reduce glucose absorption. }\end{array}$ \\
& Mean HbAc reductions \\
Glycaemic efficacy and & - As monotherapy vs. placebo: $-1.1 \%$ \\
indications & - As add-on therapy to other non-insulin agents: $-0.9 \%$ \\
& - Ass add-on to insulin: $-0.6 \%$
\end{tabular}

\section{Cardiovascular outcome trials}

\section{Hypoglycaemia}

Proven superiority vs. diet alone in obese patients - reduced all-cause mortality, diabetes related mortality and myocardial infarction, but not peripheral vascular disease or microvascular disease.

Proven superiority vs. SU and insulin in obese patients: reduced all cause mortality and stroke, but not myocardial infarction, diabetes-related deaths, peripheral vascular disease or microvascular disease.

Safety when added to SU's (glibenclamide and chlorpropamide) is unclear.

No severe hypoglycaemia as monotherapy. Some patients may have symptoms of hypoglycaemia. Can potentiate the hypoglycaemic effect of insulin or insulin secretagogues.

\section{Weight neutral or causes modest weight loss $(-1.2 \mathrm{~kg})$. No weight loss in non-diabetic individuals.}

Improves lipid profile.

Non-glycaemic benefits Reduces cancer rates in population studies.

May improve outcomes in mild to moderate heart failure; Improves laboratory measures of inflammation, coagulation, oxidative stress, endothelial function and tumour suppression; cancer rates are lower. 
Side Effects and Precautions

Dosing and prescribing
Gastrointestinal (GI) side-effects are common, are not dose-dependent, and occur in 20-30\% of patients (diarrhoea, nausea, vomiting, cramping, bloating and flatulence). Up tp $10 \%$ will discontinue therapy due to Gl side effects. Switching to an extended release formulation improves $\mathrm{Gl}$ tolerability and adherence.

Lactic Acidosis is rare with current usage (0.04 cases per 1000 patient years) and not different to non-metformin users. Metformin should be discontinued at the time of, or before an iodinated contrast imaging procedure or general anaesthesia in the following categories of patients: those with an eGFR $<60 \mathrm{~mL} / \mathrm{minute} / 1.73 \mathrm{~m}^{2}$; those with a history of liver disease, alcoholism, or heart failure; those who will receive intra-arterial iodinated contrast. Re-evaluate eGFR 48 hours after the procedure and restart metformin if renal function is stable and the patient is eating normally.

Can cause low levels of serum vitamin $B_{12}$ in 7-30\% of long-term users, but is rarely associated with the clinical features of vitamin $B_{12}$ deficiency. The exact mechanism and significance is unknown. There is no recommendation to screen for vitamin $B_{12}$ deficiency routinely. Investigate and manage vitamin $B_{12}$ deficiency according to standard clinical practice, with a high index of suspicion in patients who are vegetarian or anaemic, or have peripheral neuropathy.

Metformin (standard release): Dose range is $500 \mathrm{mg} /$ day to $3000 \mathrm{mg} /$ day in two or three divided doses with meals. Optimum glycaemic efficacy is achieved with $2000 \mathrm{mg} /$ day; few patients have additional glycaemic benefit with higher doses. The optimum dose for cardiovascular benefit in obese patients is $2550 \mathrm{mg} / \mathrm{day}$.

Metformin extended-release: Dose range is $500 \mathrm{mg} /$ day to $2000 \mathrm{mg} /$ day as a single dose with the evening meal. The $2000 \mathrm{mg}$ dose can be split to $1000 \mathrm{mg}$ twice daily without losing efficacy.

Start with $500 \mathrm{mg} /$ day of standard metformin tablets, and increase the dose by $500 \mathrm{mg}$ every one to two weeks to minimise side effects. If $\mathrm{Gl}$ side effects occur reduce the dose and re-titrate slowly. If Gl disturbances persist try switching to the extended-release formulation.

$\begin{array}{cc}\text { eGFR } \geq \mathbf{6 0 ~} \mathbf{~ m l} / \mathbf{m i n} & \mathbf{4 5 - 6 0 ~} \mathbf{~ l} / \mathbf{m i n} \\ \text { Standard dosing. } & \text { Standard dosing. } \\ \text { Monitor eGFR annually } & \text { Monitor eGFR } \\ & 3 \text { to } 6 \text { monthly }\end{array}$

\section{$<30 \mathrm{ml} / \mathrm{min}$}

Metformin is

contraindicated
Maximum dose:

$1000 \mathrm{mg} / \mathrm{day}$

Monitor eGFR 3 to 6 monthly

\section{SEMDSA 2017 Recommendations for metformin}

Initiate standard-release metformin therapy in all newly diagnosed obese patients with type 2 diabetes.

Initiate standard-release metformin therapy in all newly diagnosed non-obese patients with type 2 diabetes.

Dosing: Start with $500 \mathrm{mg}$ once daily and up-titrate the dose slowly every 10 to 14 days until glycaemic targets are met or side effects occur. Few patients will achieve and maintain glycaemic targets with $500 \mathrm{mg}$ once daily. Most patients will require 1000 $-2550 \mathrm{mg}$ per day in two or three divided doses. The optimum dose for cardiovascular benefit in obese patients is $2550 \mathrm{mg} /$ day (850 mg TDS).

If gastrointestinal (GI) adverse events are limiting, try temporarily reducing or discontinuing the drug, and re-titrate when the $\mathrm{Gl}$ disturbances resolve. The Gl side-effects with metformin extended-release is not different to the standard release when used as initial therapy; however patients who switch due to the extended release may have improved tolerability. If $\mathrm{Gl}$ disturbances remain intolerable with standard metformin tablets, try switching to a metformin extended release (XR) formulation and titrate the dose every 10-14 days again.

The extended release formulation should be dosed once daily with the evening meal at a dose not exceeding $2000 \mathrm{mg} /$ day. The $2000 \mathrm{mg}$ dose can be taken as $1000 \mathrm{mg}$ twice a day without disadvantages if the patient so prefers. Patients not achieving their glycaemic target with $2000 \mathrm{mg}$ of the extended release may benefit from switching to a higher dose of the standard release metformin.

Monitor renal function (eGFR) in all patients at least annually. Do not exceed $1000 \mathrm{mg} /$ day if the eGFR is

$30-45 \mathrm{ml} / \mathrm{min} / 1.73 \mathrm{~m}^{2}$. Stop metformin therapy if the eGFR is $<30 \mathrm{ml} / \mathrm{min} / 1.73 \mathrm{~m}^{2}$.

The significance of low serum vitamin $\mathrm{B}_{12}$ levels associated with long-term metformin use is not known. Measure and treat whenever clinically appropriate.

Profile of the patient in whom metformin may not be a preferred option:

Patients with irritable bowel syndrome or other chronic gastrointestinal disorders

Normal weight individuals who do not wish to lose weight

Patients at high risk for lactic acidosis (severe heart, lung, liver, renal or peripheral vascular disease)

There is a history of metformin intolerance.

\section{Do not persist with any chosen treatment if the $\mathrm{HbA}_{1 \mathrm{c}}$ has not decreased by $>0.5 \%$ after six months}




\title{
9.2: Drug Summary - Gliclazide modified-release
}

\author{
SEMDSA Type 2 Diabetes Guideline Expert Committee
}

(Refer to appendix 9.2 for full text and references) $\begin{array}{ll}\text { Mode of action } & \text { Gliclazide modified-release is a sulphonylurea (SU) and insulin secretagogue that binds selectively to the } \\ \text { sulphonylurea receptor-1A (SUR1A) binding-site of } \mathrm{K}_{\text {ATP }} \text { channels on pancreatic beta cells resulting in membrane } \\ \text { depolarization, calcium influx and exocytosis of stored insulin. }\end{array}$

Glycaemic efficacy and When used as monotherapy or as add-on to other non-insulin glucose lowering drugs the mean $\mathrm{HbA}$ indications reduction is $-1 \%$ with sustained efficacy beyond 2 years.

The ADVANCE study, using a gliclazide modified-release intensive treatment strategy achieved an $\mathrm{Hb}_{1 c} \operatorname{target}$ of $6.5 \%$ (vs. $7.3 \%$ for conventional treatment) and demonstrated a significant reduction in microvascular outcomes (and therefore also the combined microvascular and macrovascular outcomes), driven mainly by the

Cardiovascular outcome trials reduction in the incidence of nephropathy.

There have been no dedicated cardiovascular safety studies with any sulphonylurea. Meta-analyses of observational and randomized controlled trials consistently demonstrate that gliclazide has a better cardiovascular safety profile than glibenclamide and glimepiride.

$\begin{array}{ll}\text { Hypoglycaemia } & \begin{array}{l}\text { Gliclazide modified-release increases the risk of hypoglycaemia when used as monotherapy or combination } \\ \text { therapy, but this is significantly lower when compared to glibenclamide and glimepiride. The rates of } \\ \text { hypoglycaemia increase with lower glycaemic targets. }\end{array} \\ \text { Weight } & \text { Weight change ranges from } 0 \text { to }+1.5 \mathrm{~kg} . \text { Mean weight gain in a meta-analysis of RCTs was } 0.5 \mathrm{~kg} . \\ \text { Non-glycaemic benefits } & \begin{array}{l}\text { Gliclazide modified-release increases peripheral insulin sensitivity, decreases hepatic glucose production, } \\ \text { inhibits platelet aggregation and adhesion, increases t-PA activity and has antioxidant effects. There are also } \\ \text { reports of possibly a lower cancer risk compared to other SUs and insulin. }\end{array}\end{array}$

$\begin{array}{ll}\text { Side Effects and Precautions } & \text { Side-effects apart from hypoglycaemia and weight gain are rare. Cross-reac } \\ \text { allergy is uncommon and is not a contra-indication. } \\ \text { Do not use with advanced liver disease because of hepatic metabolism. }\end{array}$

- The usual starting dose for gliclazide modified-release is 30 to $60 \mathrm{mg}$ administered once daily with the morning meal.

- Consider starting with the higher $(60 \mathrm{mg})$ dose when the $\mathrm{HbA}_{1 \mathrm{c}}$ target is more than $0.5 \%$ from the prevailing $\mathrm{HbA} A_{1}$ level, or if the patient is has symptomatic hyperglycaemia.

- The dose can be escalated by 30 to $60 \mathrm{mg}$ every one to four weeks, guided by fasting glucose levels.

Dosing and prescribing

- The maximum dose is $120 \mathrm{mg}$ administered once daily with the morning meal.

- If mild hypoglycaemia occurs unexpectedly reduce the dose by 30 to $60 \mathrm{mg}$.

- A single episode of severe hypoglycaemia or recurrent episodes of mild hypoglycaemia would be a strong indication to switch to an alternative glucose lowering drug.

- The $60 \mathrm{mg}$ tablets are scored and can be broken to improve cost effectiveness.

Renal dosing

Current guidelines recommend that gliclazide modified-release can be used at all stages of chronic kidney disease using standard dosing guidelines. Caution is advised however, when the eGFR is

$<30 \mathrm{ml} / \mathrm{min} / 1.73 \mathrm{~m}^{2}$, and these patients with CKD stage 3 or worse should be managed with specialist supervision.

Cost of cheapest formulation at $\mathrm{R} 93.00 \mathrm{for} 120 \mathrm{mg}$ (Single exit price as at March 2017).

maximum dose

\section{SEMDSA 2017 Recommendations for sulphonylureas}

The sulphonylurea of choice should be gliclazide modified-release because:

- It has equivalent efficacy compared to other sulphonylureas.

- It is consistently associated with lower rates of hypoglycaemia and better cardiovascular and renal safety relative to other sulphonylureas.

- It has proven benefits for long-term microvascular disease outcomes.

Glibenclamide must not be used at primary care level.

Consider gliclazide modified-release as initial monotherapy when metformin is not tolerated or is contraindicated.

Consider gliclazide modified-release as add-on (dual therapy) to metformin (or other initial drug therapy) in most patients not 
To convert treatment from another sulphonylurea to gliclazide modified-release, use the following dose conversion:

- Glibenclamide $5 \mathrm{mg} \approx$ Gliclazide modified-release $30 \mathrm{mg}$

- Glimepiride 1-2 mg $\approx$ Gliclazide modified-release $30 \mathrm{mg}$

Only continue gliclazide modified-release beyond stage 3 chronic kidney disease (when the eGFR is less $30 \mathrm{ml} / \mathrm{min} / \mathrm{m}^{2}$ ) with specialist supervision.

Circumstances where gliclazide MR may be preferred to other treatment options:

- Gliclazide MR should be the preferred second drug for the majority of patients with type 2 diabetes.

- At diagnosis when rapid control of hyperglycaemic symptoms is required.

Circumstances where gliclazide MR may not be the preferred option:

- The individualised glycaemic target is $\leq 6.5 \%$ (as the risk of hypoglycaemia may be unacceptably high with this target).

- There is a history of severe hypoglycaemia or hypoglycaemia unawareness.

- There is a history of recurrent hypoglycaemia (any degree) despite dose adjustments.

- The risk of hypoglycaemia is high and/or its consequences are severe.

- The patient has advanced liver disease.

Do not persist with any chosen treatment if the HbA1c has not decreased by $>0.5 \%$ after six months

\title{
9.3: Drug Summary - Pioglitazone
}

\author{
SEMDSA Type 2 Diabetes Guideline Expert Committee
}

\section{(Refer to appendix 9.3 for optional full text and references)}

Mode of action

Glycaemic efficacy and

indications

\section{Cardiovascular outcome} trials

Hypoglycaemia

Weight

Non-glycaemic benefits

\section{Side Effects and}

Precautions

\section{Dosing and prescribing}

\section{Renal dosing}

Cost of cheapest

formulation

Agonist of nuclear receptors called peroxisome proliferator-activated receptor-gamma (PPARY). Leads to increased transcription of proteins that augment the post-receptor actions of insulin resulting in improved insulin sensitivity and B-cell function.

Good efficacy as monotherapy, dual therapy and triple therapy ( $\pm 1 \% \mathrm{HbA} \_$reduction); similar efficacy to metformin, SU or GLP-1RA.

PROactive study (secondary prevention) showed reductions in secondary endpoints (composite of all-cause mortality, non-fatal myocardial infarction, and stroke) by $16 \%$. Meta-analysis of RCTs also reported a significant $18 \%$ relative risk reduction in the composite outcome (death, myocardial infarction, or stroke). Increases heart failure hospitalisations because of fluid retention, but not mortality.

Does not cause hypoglycaemia except when combined with insulin or insulin secretagogues.

Causes dose-dependent weight gain $(\sim 2-4 \mathrm{~kg})$ due to fluid retention and adipocyte differentiation. Weight gain correlates with therapeutic response.

Increases HDL-C; reduces triglycerides, reduces LDL atherogenicity, CRP and microalbuminuria; increases PAI-1 and adiponectin; reduces carotid intima media thickness and atheroma volume. Reduces hepatic fibrosis in non-alcoholic steatohepatitis (NASH); improves ovulation and metabolic abnormalities in polycystic ovary syndrome.

Can cause fluid retention, oedema, and may worsen or precipitate congestive heart failure. Associated with an increase in distal long-bone fractures in women and men. Possible small increase in bladder cancer.

Start with 15 once daily in the morning; increase to $30 \mathrm{mg}$ after one to three months if necessary. Most patients will derive optimum benefit at this dose; do not exceed $30 \mathrm{mg}$ in the primary care setting. Maximum registered dose is $45 \mathrm{mg}$ daily.

No dose adjustment is necessary, but do not use if renal disease is causing fluid retention, or when the eGFR is $<30$ $\mathrm{ml} / \mathrm{min} / 1.73 \mathrm{~m}^{2}$.

R117.00 for $30 \mathrm{mg}$. 


\title{
SEMDSA 2017 Recommendations for pioglitazone
}

Consider pioglitazone as initial monotherapy when metformin is contraindicated or not tolerated.

Consider pioglitazone as add-on to metformin or other initial drug therapy, in selected patients not achieving or maintaining their glycaemic targets.

Consider pioglitazone as a third non-insulin glucose lowering drug in selected patients not achieving or maintaining their

Circumstances where pioglitazone may be preferred to other treatment options:

- Gliclazide MR is contraindicated or not tolerated.

- Non-alcoholic steatohepatitis is present.

- The patient has features of severe insulin resistance.

- There is a history of previous myocardial infarction, previous stroke or chronic kidney disease stage-3 (pioglitazone offers probable benefit for secondary prevention)

Circumstances where pioglitazone may not be the preferred option:

- Age > 75 years old (risk of congestive heart failure (CHF), fracture and bladder cancer)

- History of congestive heart failure.

- History of osteoporosis.

- History of bladder cancer, or haematuria that has not been investigated.

- Stage-4 or worse chronic kidney disease (risk of fluid retention).

- Patients on insulin therapy (higher risk of fluid retention and CHF).

- Elevated liver enzymes ( $>2 x$ ULN), which is not due to NASH.

\section{4: Drug summary - DPP-4-inhibitors}

\author{
SEMDSA Type 2 Diabetes Guideline Expert Committee
}

(Refer to Appendix 9.4 for review and references)

\begin{tabular}{|c|c|c|c|c|}
\hline $\begin{array}{l}\text { Mode of action and } \\
\text { pharmacology }\end{array}$ & \multicolumn{4}{|c|}{$\begin{array}{l}\text { DPP-4 inhibitors (gliptins) are capable of inhibiting the degradation of endogenous GLP-1, thereby therapeutically } \\
\text { raising circulating GLP-1 levels. }\end{array}$} \\
\hline $\begin{array}{l}\text { Glycaemic efficacy and } \\
\text { indications }\end{array}$ & \multicolumn{4}{|c|}{$\begin{array}{l}\text { Can be used as monotherapy in selected patients when there is intolerance to metformin (where there is a high risk } \\
\text { for hypoglycaemia). } \\
\text { Can be used as dual or triple therapy when added to metformin / sulphonylurea / SGLT } 2 \text { inhibitor / insulin. } \\
\text { HbAı reduction when used as monotherapy is between } 0.5 \text { and } 1.1 \% \text {. }\end{array}$} \\
\hline $\begin{array}{l}\text { Macrovascular and } \\
\text { Mortality Outcomes }\end{array}$ & \multicolumn{4}{|c|}{$\begin{array}{l}\text { Cardiovascular outcome safety trials for all } 3 \text { DPP-4 inhibitors have been neutral for major adverse cardiovascular } \\
\text { events. Saxagliptin was associated with increased rates of hospitalisation for heart failure. }\end{array}$} \\
\hline Hypoglycaemia & \multicolumn{4}{|c|}{$\begin{array}{l}\text { Hypoglycaemia rates are not different to placebo except when DPP } 4 \text { inhibitors are combined with insulin or insulin } \\
\text { secretagogues. }\end{array}$} \\
\hline Non-glycaemic benefits & \multicolumn{4}{|l|}{ Weight-neutral. } \\
\hline $\begin{array}{l}\text { Side Effects and } \\
\text { Precautions }\end{array}$ & \multicolumn{4}{|c|}{ Increased risk of hospitalisation for heart failure with saxagliptin. } \\
\hline Contraindications & \multicolumn{4}{|c|}{$\begin{array}{l}\text { Acute, chronic or recurrent pancreatitis or high risk for pancreatitis. } \\
\text { Pancreatic cancer. } \\
\text { All are contraindicated in severe liver disease. Use saxagliptin and vildagliptin with caution in moderate liver } \\
\text { disease. } \\
\text { Heart failure (saxagliptin). }\end{array}$} \\
\hline \multirow{4}{*}{ Dosing } & $\underline{e G F R}$ & Saxagliptin & Sitagliptin & Vildagliptin \\
\hline & $\geq 50 \mathrm{ml} / \mathrm{min}$ & 5 mg daily & 100 mg daily & $50 \mathrm{mg}$ twice a day \\
\hline & $30-50 \mathrm{ml} / \mathrm{min}$ & $2.5 \mathrm{mg}$ daily & 50 mg daily & 50 mg daily \\
\hline & $<30 \mathrm{ml} / \mathrm{min}$ & 2.5 mg daily & 25 mg daily & 50 mg daily \\
\hline
\end{tabular}




\title{
SEMDSA 2017 Recommendations for DPP-4 inhibitors
}

Consider a DPP-4 inhibitor as initial monotherapy when metformin is contraindicated or not tolerated.

Consider a DPP-4 inhibitor as add-on to metformin or other initial drug therapy, in selected patients not achieving or maintaining

A their glycaemic targets.

Consider a DPP-4 inhibitor as the third glucose lowering drug in selected patients not achieving or maintaining their glycaemic targets on an existing oral two-drug regimen.

Combination DPP-4 inhibitor and insulin therapy should be initiated at specialist level.

Circumstances where a DPP-4 inhibitor may be preferred to other treatment options:

- As the $2^{\text {nd }}$ add-on drug when gliclazide MR is contraindicated or not tolerated.

- As the $3^{\text {rd }}$ add on drug for most patients if $\mathrm{HbA}_{1} \mathrm{c}$ targets are potentially achievable.

- Older patients with multiple comorbidities.

- Patients with stage-4 chronic kidney disease (can be used without risk of hypoglycaemia).

- If a fixed-dose combination tablet will improve adherence, compliance and/or cost-effectiveness.

Circumstances where a DPP-4 inhibitor may not be the preferred option:

- Very high $\mathrm{HbA}_{1} \mathrm{c}$ and the glycemic target is not likely to be achieved with a DPP-4 inhibitor.

- History of pancreatitis or pancreatic tumour.

- History of heart failure or high risk of heart failure (saxagliptin).

- Liver disease: moderate (do not use saxagliptin or vildagliptin) or severe (do not any DPP-4 inhibitor).

Do not persist with any chosen treatment if the $\mathrm{HbA}_{1 \mathrm{c}}$ has not decreased by $>0.5 \%$ after six months

\section{5: Drug summary - GLP-1 receptor agonists}

\author{
SEMDSA Type 2 Diabetes Guideline Expert Committee
}

\section{(Refer to Appendix 9.5 for drug review and references)}

\begin{tabular}{|c|c|}
\hline $\begin{array}{l}\text { Mode of action and } \\
\text { pharmacology }\end{array}$ & $\begin{array}{l}\text { GLP-1 receptor agonists are modified GLP-1 molecules that have structural homology with endogenous GLP-1 but } \\
\text { are resistant to the enzymatic cleavage by DPP- } 4 \text {. }\end{array}$ \\
\hline $\begin{array}{l}\text { Glycaemic efficacy and } \\
\text { indications }\end{array}$ & $\begin{array}{l}\text { Reduces } \mathrm{HbA} \text { c by } 0.9 \text { to } 1.2 \% \text {. } \\
\text { Monotherapy: registered (liraglutide) but not recommended for primary healthcare. } \\
\text { Dual therapy: registered but not recommended for primary healthcare. } \\
\text { Triple therapy: Can be combined with any } 2 \text { of metformin / sulphonylurea / TZD. } \\
\text { Do not combine with DPP-4 inhibitor or SGLT2 inhibitor. } \\
\text { Exenatide can be as added to basal insulin with or without oral agents. }\end{array}$ \\
\hline $\begin{array}{l}\text { Macrovascular and } \\
\text { Mortality Outcomes }\end{array}$ & $\begin{array}{l}\text { Lixisenatide was neutral in the ELIXA trial. } \\
\text { Liraglutide and semaglutide have each demonstrated reductions in a composite endpoint of major adverse } \\
\text { cardiovascular events by } 13 \% \text { and } 26 \% \text { in the LEADER and SUSTAIN- } 6 \text { trials respectively (vs. placebo), when used in } \\
\text { patients with established cardiovascular disease. } \\
\text { There are no cardiovascular outcomes trials with exenatide. }\end{array}$ \\
\hline Hypoglycaemia & $\begin{array}{l}\text { Hypoglycaemia rates are not different to placebo except when GLP-1 receptor agonist are combined with insulin or } \\
\text { insulin secretagogues. }\end{array}$ \\
\hline Non-glycaemia benefits & $\begin{array}{l}\text { Weight reduction of between } 1 \text { and } 3 \mathrm{~kg} \text { for exenatide and liraglutide. } \\
\text { Both exenatide and liraglutide reduce SBP and DBP by } 1 \text { to } 5 \mathrm{mmHg} \text {. } \\
\text { Reduction in liver fat content (liraglutide). }\end{array}$ \\
\hline $\begin{array}{l}\text { Side Effects and } \\
\text { Precautions }\end{array}$ & $\begin{array}{l}\text { Nausea and vomiting in up to } 25 \% \text {; Discontinuation rate } 5-20 \% \text {. } \\
\text { Pancreatitis. } \\
\text { Skin reactions. }\end{array}$ \\
\hline Contraindications & $\begin{array}{l}\text { History of pancreatitis, or at high risk for pancreatitis (e.g. untreated gallstone disease, recent or planned ERCP, } \\
\text { excessive alcohol use). } \\
\text { History of pancreatic tumour. } \\
\text { History of medullary thyroid cancer (MTC) or multiple endocrine neoplasia (MEN) syndrome type } 2\end{array}$ \\
\hline Dosing & 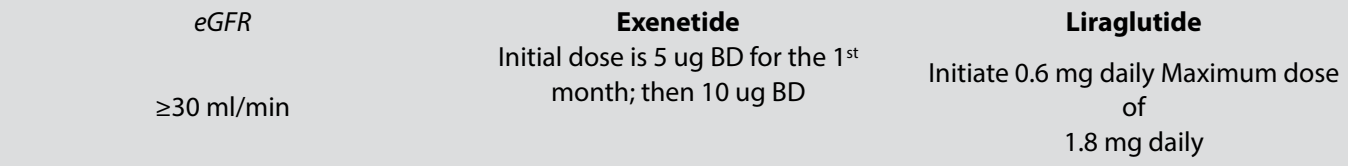 \\
\hline & Contraindicated \\
\hline
\end{tabular}




\section{SEMDSA 2017 Recommendations for GLP-1 receptor agonists (GLP-1RA)}

Consider a GLP-1RA injectable as the third glucose lowering drug (triple therapy) in overweight and obese patients when glycaemic targets are not being achieved or maintained.

Consider adding a GLP-1RA to existing basal insulin therapy (with oral therapies) as an alternative to intensifying the insulin regimen, especially when weight gain and/or hypoglycaemia is a limiting factor.

Escalate the dose of GLP-1RA slowly to minimise side-effects.

Circumstances where a GLP-1RA may be preferred to other treatment options:

- Overweight and obese patients

- Weight gain or hypoglycaemia has been, or is likely to be problematic with other treatment options.

- $\mathrm{Hb} \mathrm{A}_{1} \mathrm{c}$ is very high (GLP-1RA and insulin are the most effective glucose lowering drugs for most patients).

- Patients with established cardiovascular disease (liraglutide benefit); to be managed at specialist care level.

\section{6: Drug Summary - SGLT2 inhibitors}

SEMDSA Type 2 Diabetes Guideline Expert Committee

\section{(Refer to Appendix 9.6 for review and references)}

$\begin{array}{ll}\text { MOA } & \begin{array}{l}\text { By inhibiting SGLT2, gliflozins reduces renal glucose reabsorption, leading to increased urinary excretion of excess } \\ \text { glucose and a reduction in plasma glucose concentrations in a non-insulin dependent manner. }\end{array} \\ & \text { As monotherapy: } 0.6 \% \text { to }-1.2 \% \text {; non-inferior to metformin. } \\ \text { Glycaemic efficacy and } & \text { As add on to metformin: }-0.5 \% \text { to }-1.0 \% \text {; non-inferior to other classes } \\ \text { indications } & \text { As add on to metformin + SU: }-0.7 \% \text { to }-0.9 \% \text {; non-inferior to DPP- } 4 \text { inhibitors } \\ & \text { As add on to insulin therapy: }-0.5 \% \text { to }-0.8 \%\end{array}$

Microvascular Outcomes No primary outcome studies.

Macrovascular and

Mortality Outcomes

\section{Hypoglycaemia}

Non-glycaemic benefits
Empagliflozin therapy was associated with a reduction in all-cause death, cardiovascular-death and hospitalisation for heart failure in patients with established cardiovascular disease. There has been no signal of adverse cardiovascular outcomes in systematic meta-analyses for the other SGLT2 inhibitors.

Hypoglycaemia rates are not different to placebo except when SGLT2 inhibitors are combined with insulin or insulin secretagogues.

Mean weight loss of 1.6 to $2.5 \mathrm{~kg}$; not different to GLP-1RAs (meta-analysis) Systolic and diastolic blood pressure reduction $(-4.0$ and $-1.5 \mathrm{mmHg}$ ) respectively.

Mycotic genital infections are common (and more so in women); do not use in patients with a history of recurrent genital infections.

The risk of urinary tract infections may be increased but can be minimised by advising adequate hydration and fastidious bathroom hygiene; do not prescribe SGLT2 inhibitors in patients with a history of recurrent UTI.

Dehydration and hypotension can occur particularly in susceptible patients (treated with loop diuretics, have advanced cardiac disease or older than 65 years). Always ensure and emphasise adequate hydration when prescribing SGLT2 inhibitors.

Side effects and precautions
eGFR usually declines within the first weeks of initiating therapy and then gradually returns toward baseline. Monitor eGFR and discontinue SGLT2 inhibitors if the decline is $\geq 30 \%$.

Diabetic ketoacidosis may occur at mildly elevated levels of blood glucose particularly in insulin treated patients. Warn patients of the symptoms of DKA and advise them to seek medical attention immediately.

The risk of fractures and lower-limb (especially toe) amputations is increased with canagliflozin. Therefore do not use canagliflozin, and exercise caution with the other drugs in this class, in patients who are at high risk for these conditions.

Do not prescribe dapagliflozin to patients with bladder cancer or in combination with pioglitazone. 


\begin{tabular}{|c|c|c|c|c|}
\hline \multirow{4}{*}{ Dosing } & $e G F R$ & Dapagliflozin & Empagliflozin & Canagliflozin \\
\hline & $\geq 60 \mathrm{ml} / \mathrm{min}$ & $5 \mathrm{mg}$ or $10 \mathrm{mg}$ & $10 \mathrm{mg}$ or $25 \mathrm{mg}$ & $100 \mathrm{mg}$ or $300 \mathrm{mg}$ \\
\hline & $45-60 \mathrm{ml} / \mathrm{min}$ & Contraindicated & $\begin{array}{c}\text { Continue } 25 \mathrm{mg} \text { but do } \\
\text { not initiate therapy }\end{array}$ & $\begin{array}{c}\text { Continue } 100 \mathrm{mg} \text { but do } \\
\text { not initiate therapy }\end{array}$ \\
\hline & $<45 \mathrm{ml} / \mathrm{min}$ & Contraindicated & Contraindicated & Contraindicated \\
\hline Cost & n; not regis & rica as at March & & \\
\hline
\end{tabular}

\section{SEMDSA 2017 Recommendations for SGLT2 inhibitors}

Do not use SGLT2 inhibitors as initial monotherapy

Consider a SGLT2 inhibitor as add-on (dual therapy) to metformin (or other initial drug therapy) in selected patients not achieving or maintaining their glycaemic targets.

Consider a SGLT2 inhibitor as the $3^{\text {rd }}$ glucose lowering drug in selected patients not achieving or maintaining their glycaemic targets on an existing oral two-drug regimen.

Circumstances where an SGLT2inhibitor may be preferred to other treatment options:

- Overweight and obese patients.

- Weight gain or hypoglycaemia has been, or is likely to be problematic with other treatment options.

- Patients with established cardiovascular disease (empagliflozin benefit); to be managed at specialist care level.

Circumstances where an SGLT2 inhibitor may not be the preferred option:

- Patients with recurrent mycotic genital infections or urinary tract infections.

- Patients at risk for dehydration and hypotension.

- Patients at high risk for stroke, fracture (canagliflozin), amputation (canagliflozin), bladder cancer (dapagliflozin) or ketoacidosis (refer to drug review).

Do not initiate SGLT2 inhibitors when the eGFR is $<60 \mathrm{ml} / \mathrm{min} / \mathrm{m}^{2}$.

Stop all SGLT2 inhibitors when the eGFR is $<45 \mathrm{ml} / \mathrm{min} / \mathrm{m}^{2}$.

\section{Do not persist with any chosen treatment if the $\mathrm{HbA}_{1 \mathrm{c}}$ has not decreased by $>0.5 \%$ after six months}

\section{7: Alpha-glucosidase inhibitors (acarbose)}

SEMDSA Type 2 Diabetes Guideline Expert Committee

\begin{tabular}{|c|c|c|}
\hline Mechanism of Action & $\begin{array}{l}\text { Prevents the conversion of complex carbohydrates into monosaccharides within the intestine thereby } \\
\text { decreasing the ability to absorb monosaccharides. }\end{array}$ & \\
\hline $\begin{array}{l}\text { Glycaemic efficacy and } \\
\text { indications }\end{array}$ & $\mathrm{HbA}_{1} \mathrm{c}$ reduction when used as monotherapy of between 0.6 and $0.8 \%$. & A \\
\hline Microvascular Outcomes & Reduction of Microvascular Complications are inferred from the benefit of improved glycaemic control. & B \\
\hline $\begin{array}{l}\text { Macrovascular and } \\
\text { Mortality Outcomes }\end{array}$ & $\begin{array}{l}\text { Acarbose significantly reduced the risk of cardiovascular events by } 49 \% \text { in patients with impaired glucose } \\
\text { tolerance. No data for patients with Diabetes. }\end{array}$ & B \\
\hline Hypoglycaemia & $\begin{array}{l}\text { Hypoglycaemia rates are no different to placebo except when combined with Insulin or Insulin } \\
\text { Secretagogues. }\end{array}$ & $\mathrm{B}$ \\
\hline Non glycaemic benefits & Weight neutral. & B \\
\hline $\begin{array}{l}\text { Side Effects and } \\
\text { Precautions }\end{array}$ & $\begin{array}{l}\text { Transient elevation of hepatic transaminases. } \\
\text { Gastrointestinal Side Effects (Flatulence and diarrhoea). }\end{array}$ & B \\
\hline \multirow[t]{2}{*}{ Dosing } & $\begin{array}{c}\text { Acarbose } \\
\qquad 30 \mathrm{ml} / \mathrm{min} \quad \text { Start with } 50 \mathrm{mg} \text { once daily with meals, and increase by } 50 \mathrm{mg} \text { every } \\
\text { two weeks if tolerated. } \\
\text { Maximum dose is } 100 \mathrm{mg} \times 3 \text { daily. }\end{array}$ & \\
\hline & Not recommended & \\
\hline Cost & High (R407.00). & \\
\hline
\end{tabular}

